\title{
What's Real About the Business Cycle?
}

\author{
James D. Hamilton
}

This paper argues that a linear statistical model with homoskedastic errors cannot capture the nineteenth-century notion of a recurring cyclical pattern in key economic aggregates. A simple nonlinear alternative is proposed and used to illustrate that the dynamic behavior of unemployment seems to change over the business cycle, with the unemployment rate rising more quickly than it falls. Furthermore, many but not all economic downturns are also accompanied by a dramatic change in the dynamic behavior of short-term interest rates. It is suggested that these nonlinearities are most naturally interpreted as resulting from short-run failures in the employment and credit markets and that understanding these short-run failures is the key to understanding the nature of the business cycle.

Federal Reserve Bank of St. Louis Review, July/August 2005, 87(4), pp. 435-52.

\section{WHAT IS THE BUSINESS CYCLE?}

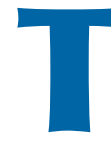
"he term "cycle" is used to describe a process that moves sequentially between a series of clearly identifiable phases in a recurrent or periodic fashion. Economists of the nineteenth and early twentieth centuries were persuaded that they saw such a pattern exhibited in the overall level of economic activity and enthusiastically sought to characterize the observed regularities of what came to be known as the "business cycle." The most systematic and still-enduring summaries of what seems to happen during the respective phases were provided by Mitchell $(1927,1951)$ and Burns and Mitchell (1946).

The expression "business cycle theory" remains in common usage today, even though, in most of the modern models that wear the label, there in fact is no business cycle in the sense just described. These are models of economic fluctuations, to be sure, but they do not exhibit clearly articulated phases through which the economy could be said to pass in a recurrent pattern.
In part, this shift in the profession's conception of what needs to be explained about business fluctuations reflects a desire to integrate the determinants of long-run economic growth and the causes of short-run economic downturns within a single unified theory of aggregate economic performance. Since improvements in overall productivity are widely acknowledged to be one of the key factors driving long-run growth, and since such improvements cannot reasonably be expected to occur at a constant rate over time, it is natural to explore the possibility that variation over time in the rate of technological progress could be a primary cause of variation over time in the level of economic activity. Brock and Mirman (1972) were the first to incorporate stochastic variation in the rate of technical progress into a neoclassical growth model, though they clearly intended this as a model of long-run growth rather than a realistic description of short-run fluctuations. Kydland and Prescott (1982) later took the much bolder step of proposing that this class of models might explain variations in economic activity at all fre-

James D. Hamilton is a professor of economics at the University of California, San Diego. This research was supported by the National Science Foundation under grant No. SES-0215754.

(C) 2005, The Federal Reserve Bank of St. Louis. Articles may be reprinted, reproduced, published, distributed, displayed, and transmitted in their entirety if copyright notice, author name(s), and full citation are included. Abstracts, synopses, and other derivative works may be made only with prior written permission of the Federal Reserve Bank of St. Louis. 


\section{Hamilton}

quencies, in what has come to be known as "real business cycle models."

Although unifying growth and business cycle theory holds tremendous aesthetic appeal, this particular solution is not without its detractors. Indeed, the reasons that Irving Fisher gave in 1932 for rejecting such an approach have in the opinion of many yet to receive a satisfying response from modern real business cycle theorists:

[I]n times of depression, is the soil less fertile? Not at all. Does it lack rain? Not at all. Are the mines exhausted? No, they can perhaps pour out even more than the old volume of ore, if anyone will buy. Are the factories, then, lamed in some way—down at the heel? No; machinery and invention may be at the very peak.

(Fisher, 1932, p. 5)

Continuing along the lines of Fisher's reasoning, the size of the population places an obvious physical limit on how much a given nation can produce and is certainly a key reason that aggregate output increases over time. But just as surely, a decrease in population is not the cause of the decrease in employment that we observe in times when the unemployment rate is shooting up dramatically. There is in this respect an obvious inherent asymmetry in fluctuations in the number of workers employed - the measure must go up for different reasons than it goes down. A parallel argument can be made in terms of the capital stock, another key factor determining long-run growth, which again places an upper limit on how much a country can produce. Yet in times when we see all measures of capacity utilization falling, the natural inference is that some forces other than the quantity or quality of available manufacturing facilities account for the drop in aggregate output.

If we agree that these three factors-technology, labor force, and the capital stock-are the three main determinants of long-run economic growth, we might greet with considerable skepticism the suggestion that the same three factors are in a parallel way responsible for producing the drop in real GDP that we observe during a business downturn.

The purpose of this paper is to explore whether the nineteenth-century economists were on to something that their modern descendants may have forgotten. Is there really a business cycle, or is the expression an unfortunate linguistic vestige of a less-informed era? I will argue that indeed there is a recurring pattern in the level of economic activity that needs to be explained, but that a statistical characterization of this pattern requires a nonlinear dynamic representation and calls for an asymmetric interpretation of the forces that cause employment to rise and fall. I further observe that one element of this pattern has often been a related cyclical behavior of interest rates.

To the question, "Is the business cycle real?" these findings suggest that, yes, the business cycle is real in the sense that it is a feature of the data that needs to be explained. In the other meaning of the term "real," however-the sense from which springs the label "real business cycle," namely, a cycle unrelated to monetary developments-the evidence adduced here for the importance of comovements between financial and real variables suggests that the cycle is not "real" at all or, at the least, not completely divorced from monetary developments.

\section{THE BEHAVIOR OF UNEMPLOYMENT}

Figure 1 plots the monthly unemployment rate in the United States from 1948:01 to 2004:03. ${ }^{1} \mathrm{I}$ would suggest that someone looking at such a graph for the first time would indeed be inclined to identify a repeated sequence of ups and downs, with each of the obvious sharp upswings in the unemployment rate occurring during periods that the National Bureau of Economic Research (NBER) has classified as economic recessions (indicated by shaded regions on the graph).

Although one's eye is sympathetic to the claim that these data display a recurrent pattern, it does not appear to be cyclical in the sense of exhibiting strict periodicity. For example, the two consecutive unemployment peaks in 1958:07 and 1961:05 are separated by less than three years, whereas

\footnotetext{
1 This is the seasonally adjusted civilian unemployment rate from the Bureau of Labor Statistics; http://stats.bls.gov.
} 


\section{Figure 1}

\section{U.S. Monthly Civilian Unemployment Rate and U.S. Recessions, 1948:01-2004:03}

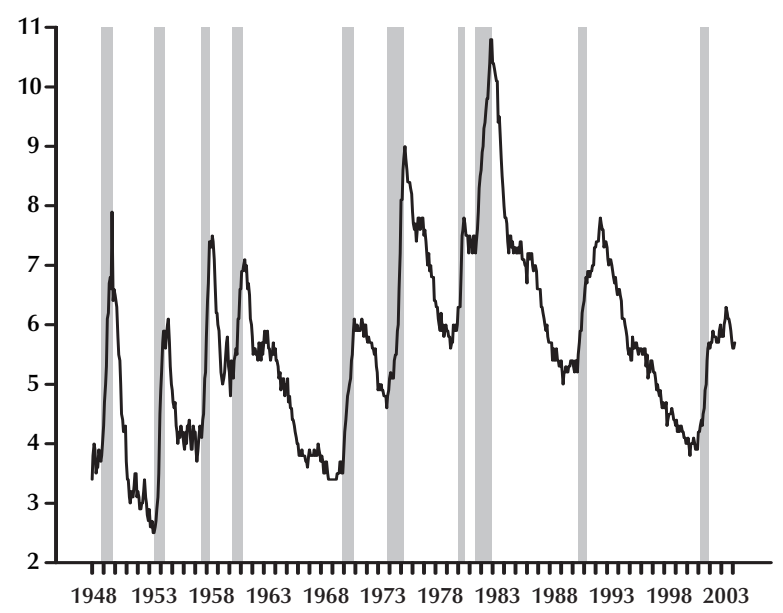

those of 1982:11 and 1992:06 are separated by a decade. More formally, one can look for any sort of periodic pattern by examining the spectrum of the unemployment rate, an estimate of which is plotted in Figure 2 as a function of the period of the cycle. ${ }^{2}$ If one tries to decompose the unemployment series in Figure 1 into a series of strictly periodic cycles, by far the most important of these are those with the longest period, as opposed to something regularly repeating every 3 to 5 years.

Let $y_{t}$ denote the unemployment rate. Consider an AR(2) representation of these data with Student $t$ innovations, obtained by maximizing the log likelihood function

$$
\begin{gathered}
\mathfrak{L}(\theta)=\sum_{t=3}^{T} \ell_{t}(\theta) \\
\ell_{t}(\theta)=k-[(v+1) / 2] \log \left[1+\frac{u_{t}^{2}}{v \sigma^{2}}\right]
\end{gathered}
$$

\footnotetext{
2 This was calculated by smoothing the sample periodogram with a Bartlett window (e.g., Hamilton, 1994, eq. [6.3.15]) with lag $q=13$, as calculated using the RATS fft procedure with window (type = tent, width $=25$ ). See the procedure hamp167.prg available at www.estima.com/procs_hamilton.shtml for details. The resulting estimate $\hat{s}_{Y}\left(\omega_{i}\right)$ for $\omega_{i}+2 \pi j / T$ is plotted in Figure 2 for given $j$ as a function of $T / j$, which is the variable measured on the horizontal axis.
}

\section{Figure 2}

\section{Estimated Spectrum of U.S. Monthly Civilian Unemployment Rate, 1948:01-2004:03}

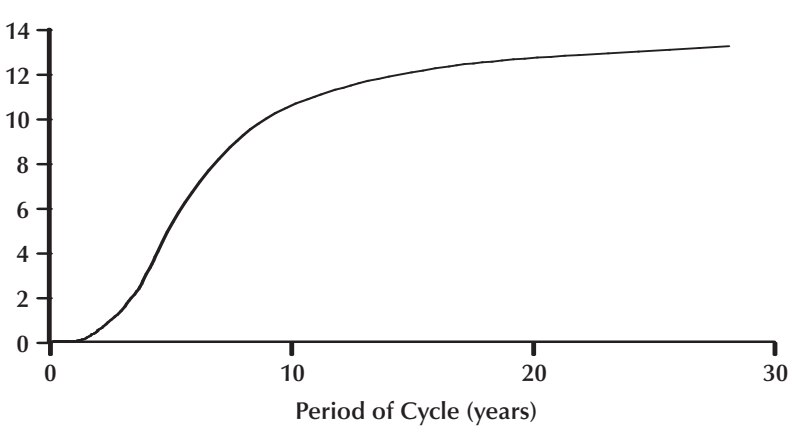

NOTE: Plotted as a function of the period of the cycle in years.

$$
\begin{gathered}
u_{t}=y_{t}-c-\phi_{1} y_{t-1}-\phi_{2} y_{t-2} \\
k=\log \{\Gamma[(v+1) / 2]\}-\log \{\Gamma[v / 2]\} \\
-(1 / 2) \log \left(\sigma^{2} v \pi\right)
\end{gathered}
$$

with respect to $\theta=\left(c, \phi_{1}, \phi_{2}, \sigma^{2}, v\right)^{\prime}$ subject to the constraints ${ }^{3}$ that $\sigma^{2}>0$ and $v>0$. These maximum likelihood estimates (MLEs) (with asymptotic standard errors in parentheses) imply that the unemployment rate $y_{t}$ for month $t$ could be modeled as follows:

(4) $y_{t}+\underset{(0.028)}{0.060}+\underset{(0.037)}{1.117} y_{t-1}-\underset{(0.037)}{0.128} y_{t-2}+\underset{(0.007)}{0.158} v_{t}$,

where $v_{t}$ is distributed Student $t$ with 4.42 degrees of freedom, with the standard error for the degreesof-freedom parameter $v$ being estimated at 0.74 . Using Student $t$ innovations instead of Normal innovations increases the log likelihood by 52.04, a huge gain from estimating the single parameter $v$ (see Table 1).

As further evidence against a cycle with regular periodicity, it is interesting to note that the roots of the second-order difference equation in (4) are both positive and real, meaning that this system does not exhibit any oscillatory behavior in response to a shock to $v_{t}$.

3 See, for example, Hamilton (1994, Section 5.9) on numerical maximization subject to inequality constraints. 
Table 1

Comparison of Selected Models of Postwar Unemployment Rates

\begin{tabular}{lccr} 
Model & No. of parameters & Log likelihood & Schwarz criterion \\
\hline Gaussian AR(2) & 4 & 75.59 & 62.57 \\
Student $t$ AR(2) & 5 & 127.63 & 111.35 \\
Student $t$ AR(2) with MS intercept & 11 & 174.58 & 138.77
\end{tabular}

NOTE: Schwarz criterion calculated as $\mathfrak{Q}-(k / 2) \log (T)$ for $\mathfrak{Q}$ the $\log$ likelihood, $k$ the number of parameters, and $T=673$ the sample size.

\section{Figure 3}

\section{Simulated Unemployment}

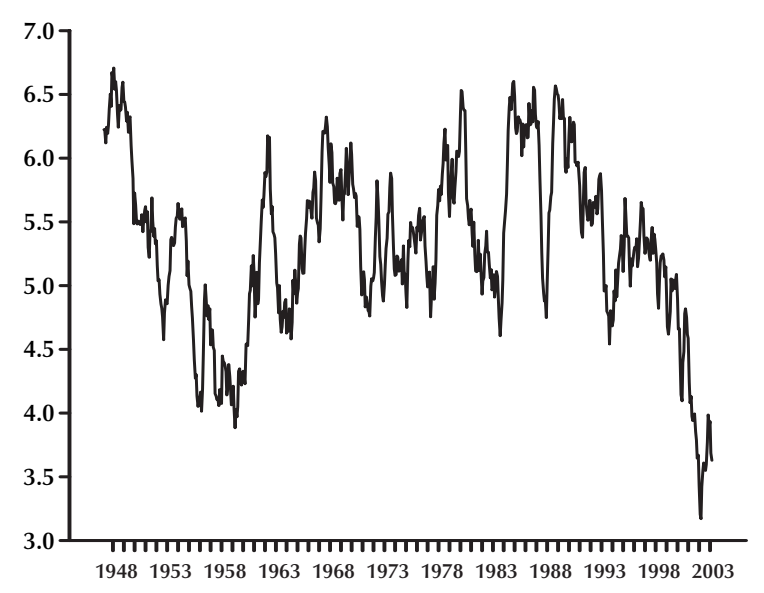

NOTE: Simulated sample generated from equation (4).

Is the appearance of a repeated cycle in Figure 1 just a figment of our imagination, then? Another interesting exercise is to simulate a timeseries realization from (4), which is displayed in Figure 3. These simulated data have the same mean, variance, and serial correlation as the real data in Figure 1, as of course they should. Even so, one has little of the sense of a recurrent cycle in these simulated data that seemed compelling in the actual data. If one were to label some of the episodes in this simulated data set as "recessions," where would they be? Indeed, expression (4) characterizes the true process from which these artificial data were simulated. What in terms of the qualities of this data-generating process would one characterize as a "business cycle?" There are good and bad values of the innovations $v_{t}$, and perhaps we could make up some rule for categorizing a relatively unlikely string of mostly negative innovations as a "recession." But any such rule would be completely arbitrary and tell us more about our imagination or quest for patterns and labels than about anything in the objective reality. There is nothing qualitatively different about a value of $v_{t}$ that puts us within the arbitrary recession category and one that leaves us just short of it.

I would argue that this inability to define a business cycle as a fundamental attribute of the data-generating process (4) is in fact inherent in any time-series model that describes $y_{t}$ as a linear function of its lagged values plus an i.i.d. innovation. Even if the linear difference equation did exhibit an oscillatory impulse-response function or imply more power in the spectrum at periods of 3 to 5 years, it seems to be some other feature of the data in Figure 1 that constitutes the "business cycle."

I would suggest instead that what we have in mind is that there is something in common between the rapid run-ups in unemployment that occurred in each of the postwar recessions, even though the length of time it takes for unemployment to spike up varies from episode to episode, and the timing separating such events is irregular. Indeed, the idea of looking for commonality across recessions whose elapsed calendar time is different for different episodes was precisely the methodology that Burns and Mitchell used to create their graphs summarizing typical business cycle patterns. Stock $(1987,1988)$ showed that such a way of thinking about data necessarily implies a nonlinear data-generating process. 
Table 2

\section{Maximum Likelihood Estimates of Three-State Markov-Switching Model for Postwar Unemployment Rate}

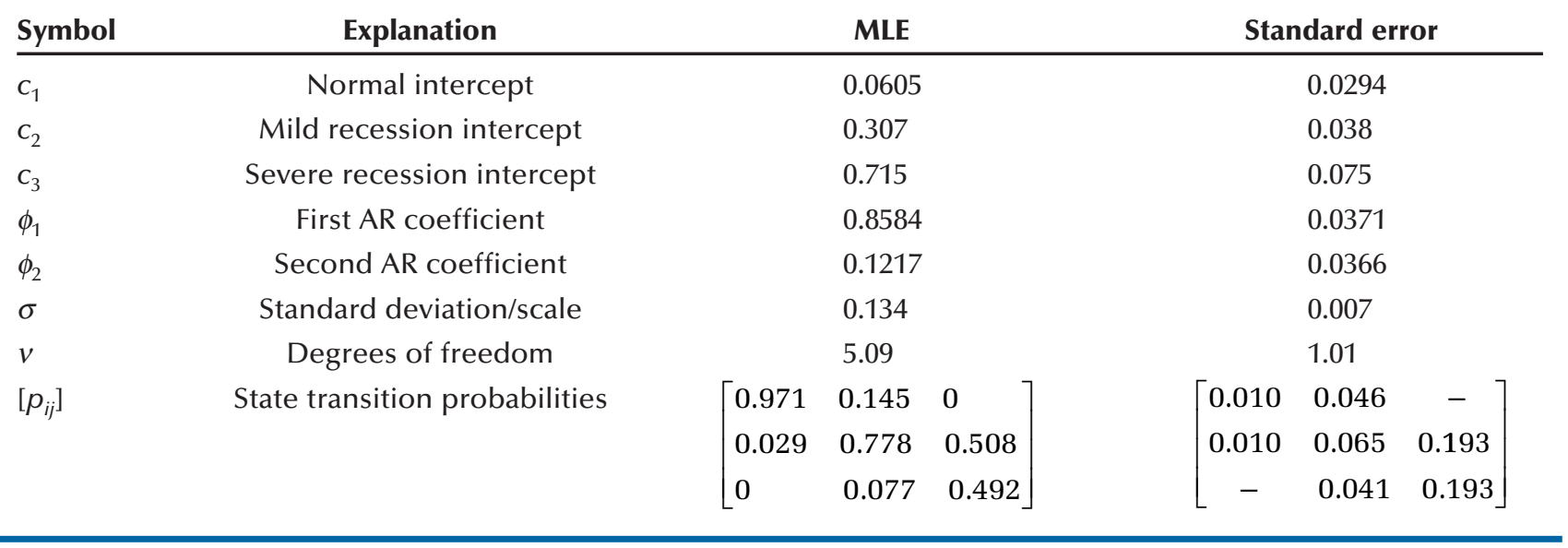

Friedman (1969, p. 274) and DeLong and Summers (1986), among others, have forcefully advanced the related proposition that asymmetry is the defining characteristic of business cycles. In particular, the asymmetry commented on in Figure 1that recessions are characterized by an unusually rapid but nonetheless transient increase in the unemployment rate-has been confirmed to be a statistically significant feature of these data in a number of recent quantitative studies, including Montgomery et al. (1998), Rothman (1998), and van Dijk, Franses, and Paap (2002).

Suppose we try in a simple way to represent the asymmetry that the eye perceives in Figure 1. One idea is that the intercept in equation (2) assumes different values in different phases of the business cycle. Consider the following generalization of (2),

$$
y_{t}=c_{s_{t}}+\phi_{1} y_{t-1}+\phi_{2} y_{t-2}+u_{t}
$$

where $s_{t}=1$ if the economy is in the normal growth state at date $t, s_{t}=2$ if it is in a mild recession, and $s_{t}=3$ for a severe recession. Suppose that the transition between these three regimes follows a Markov chain, where $p_{i j}=\operatorname{Pr}\left(s_{t}=j \mid s_{t-1}=i\right)$ is another set of nine parameters to be estimated subject to the constraints $0 \leq p_{i j} \leq 1$ and $\sum_{j=1}^{3} p_{i j}=1$. Conditional on the economy being in regime $j$ at date $t$, the unemployment rate thus has conditional log density given by

$$
\begin{aligned}
& \log f\left(y_{t} \mid s_{t}=j, y_{t-1}, y_{t-2}, \ldots, y_{1}\right) \\
& =k-[(v+1) / 2] \log \left[1+\frac{u_{j t}^{2}}{v \sigma^{2}}\right] \\
& u_{j t}=y_{t}-c_{j}-\phi_{1} y_{t-1}-\phi_{2} y_{t-2}
\end{aligned}
$$

for $k$ as in (3).

The log likelihood for the observed data,

$$
\mathfrak{L}(\theta)=\sum_{t=3}^{T} \log f\left(y_{t} \mid y_{t-1}, y_{t-2}, \ldots, y_{1} ; \theta\right),
$$

can then be calculated as in Hamilton (1994, equation [22.4.7]) and maximized numerically with respect to the population parameters $\theta=\left(c_{1}, c_{2}\right.$, $\left.C_{3}, \phi_{1}, \phi_{2}, \sigma, v, p_{11}, p_{12}, p_{13}, p_{21}, p_{22}, p_{23}, p_{31}, p_{32}, p_{33}\right)^{\prime}$. The MLEs turn out to be at the boundaries such that $p_{13}=0$ and $p_{31}=0$; that is, states 1 and 3 never follow each other. These MLEs are reported in Table 2, where in order to calculate standard errors from the second derivative matrix of the log likelihood, we went ahead and imposed the constraint $p_{13}=p_{31}=0$ so that there are just four free transition probabilities $\left(p_{11}, p_{21}, p_{22}\right.$, and $\left.p_{32}\right)$. The smoothed probabilities implied by the MLEs, $\operatorname{Pr}\left(s_{t}=j \mid y_{1}, y_{2}, \ldots, y_{T} ; \hat{\theta}\right)$, are plotted in Figure 4. 


\section{Figure 4}

\section{Smoothed Probabilities, Unemployment}

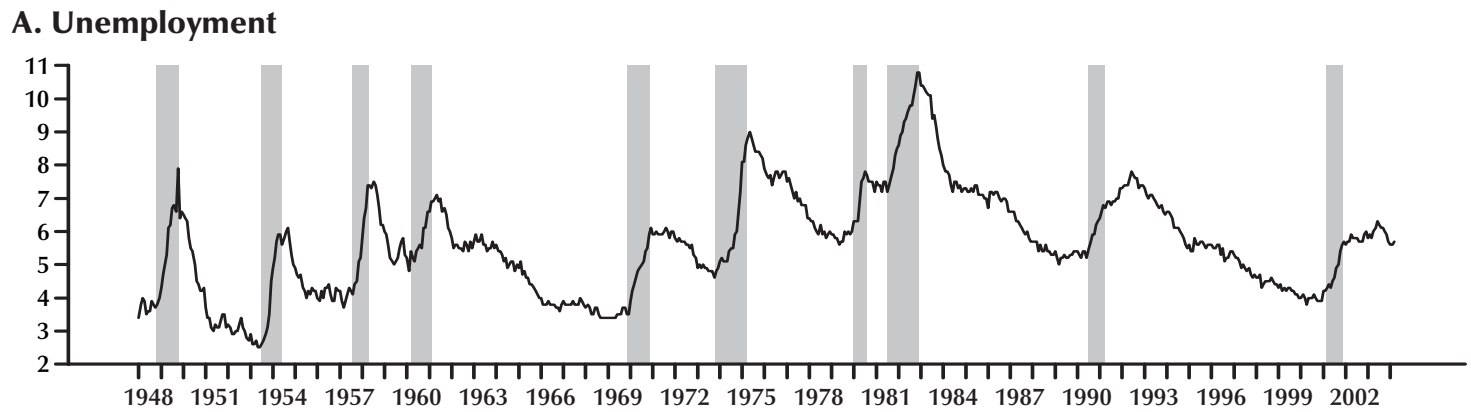

\section{B. Probability of State 2}

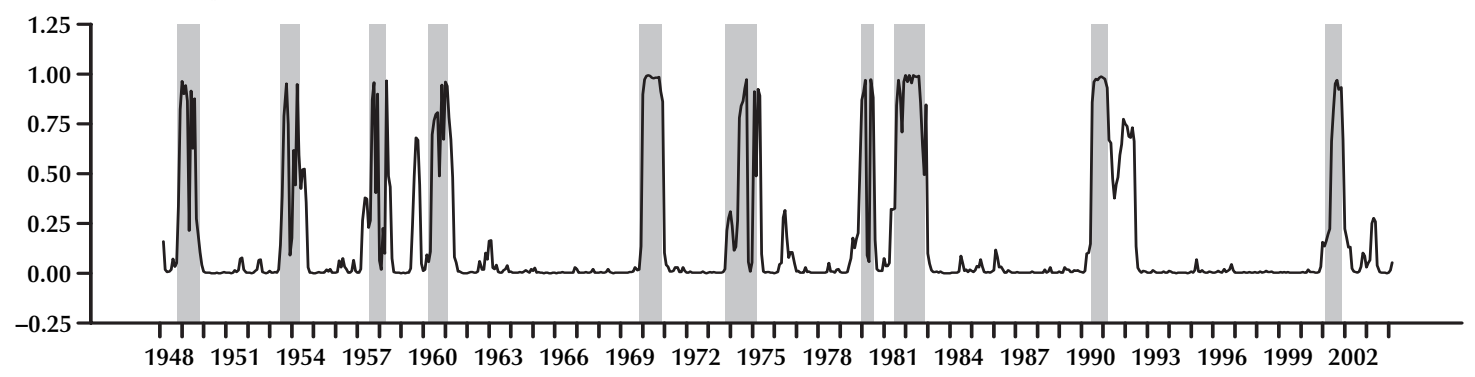

\section{Probability of State 3}

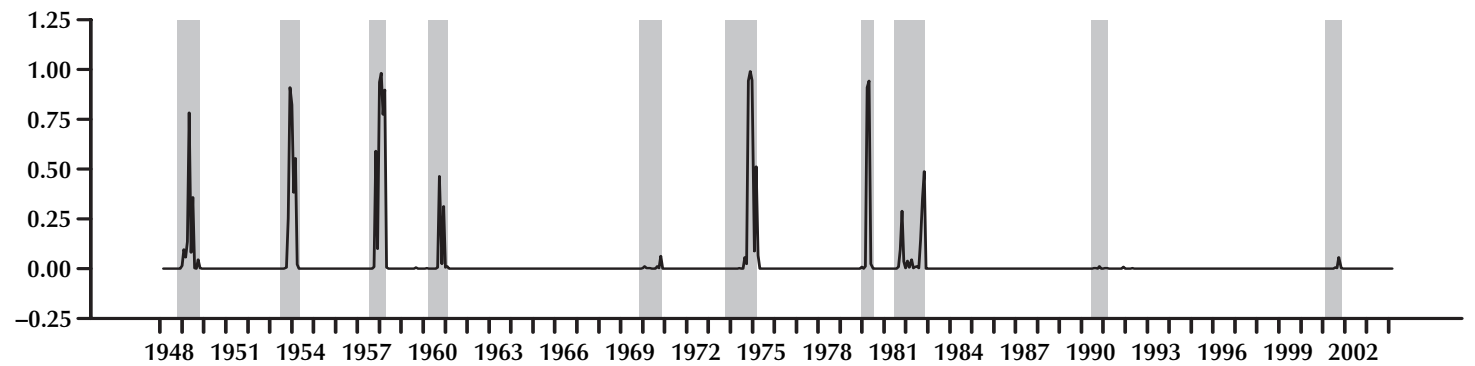

NOTE: Panel A reproduces the unemployment data from Figure 1. Panel B is for the moderate recession regime $\left(\operatorname{Pr}\left(s_{t}=2 \mid y_{1}, y_{2}, \ldots, y_{T}, \hat{\theta}\right)\right)$ and Panel $C$ is for the severe recession regime $\left(\operatorname{Pr}\left(s_{t}=3 \mid y_{1}, y_{2}, \ldots, y_{T}, \hat{\theta}\right)\right)$ for $\hat{\theta}$ the maximum likelihood estimates reported in Table 2.

Note that allowing this nonlinearity produces a further huge improvement in the log likelihood and would easily be selected on the basis of the Schwarz criterion (again see Table 1). Formal tests of the null hypothesis of no Markov switching have been proposed by Hansen (1992), Hamilton (1996), Garcia (1998), and Carrasco, $\mathrm{Hu}$, and Ploberger (2004). The latter have found the optimal test against the alternative of Markov switching, which we implement here for the special case where the alternative to (4) is a model with
Markov switching in the intercept only as in (5); for details of the Carrasco, Hu, and Ploberger test see the appendix. The test statistic on the U.S. employment data turns out to be 26.02 , whereas the 5 percent critical value is only 4.01 , providing overwhelming evidence for representing the data with the model described in Table 2 rather than (4).

Consider some of the properties of the estimated Markov-switching model. The process is stationary, allowing us to take the unconditional expectation of equation (5), 


$$
E\left(y_{t}\right)=\sum_{j=1}^{3} c_{j} \operatorname{Pr}\left(s_{t}=j\right)+\phi_{1} E\left(y_{t}\right)+\phi_{2} E\left(y_{t}\right)
$$

implying

$$
E\left(y_{t}\right)=\left(1-\phi_{1}-\phi_{2}\right)^{-1} \sum_{j=1}^{3} c_{j} \operatorname{Pr}\left(s_{t}=j\right) .
$$

The ergodic probabilities can be calculated as in Hamilton (1994, equation [22.2.26]):

$$
\left[\begin{array}{l}
\operatorname{Pr}\left(s_{t}=1\right) \\
\operatorname{Pr}\left(s_{t}=2\right) \\
\operatorname{Pr}\left(s_{t}=3\right)
\end{array}\right]=\left[\begin{array}{l}
0.810 \\
0.165 \\
0.025
\end{array}\right] .
$$

In other words, the economy spends about 80 percent of the time in the normal phase of the business cycle. Substituting these unconditional probabilities into (6), the model implies an expected unemployment rate of 5.9 percent, close to the postwar average. ${ }^{4}$ If the economy is in state $i$ at date $t$, on average it will stay there for $\sum_{k=1}^{\infty}\left(1-p_{i i}\right) k p_{i i}^{k-1}=\left(1-p_{i i}\right)^{-1}$ months. From the transition probabilities in Table 2, the expected duration of each regime is

$$
\left[\begin{array}{l}
\left(1-p_{11}\right)^{-1} \\
\left(1-p_{22}\right)^{-1} \\
\left(1-p_{33}\right)^{-1}
\end{array}\right]=\left[\begin{array}{l}
34.0 \\
4.5 \\
2.0
\end{array}\right]
$$

A typical expansion thus might last about three years. A mild recession often lasts less than half a year, at which point it might enter the more severe phase for a few months and then spend another half year again at moderately high unemployment rates before coming back down.

Figure 5 displays the way in which this representation captures the asymmetry of the business cycle discussed here previously. Suppose the economy is currently experiencing an unemployment rate of 6 percent but is in the recovery phase of the cycle $\left(s_{t}=1\right)$. In the absence of any new shocks $\left(u_{t+j}=0\right.$ for all $\left.j\right)$, the dynamic behavior of the unemployment rate over time would be given by

4 Unlike ordinary least squares, the maximum likelihood estimates in this case do not imply an estimate of the population mean that is equal by construction to the sample mean.

$$
y_{t+j}=0.0605+0.8584 y_{t+j-1}+0.1217 y_{t+j-2}
$$

for $j=1,2, \ldots$ starting from $y_{t}=y_{t-1}=6.0$. The top panel of Figure 5 plots this path for $y_{t+j}$ as a function of $j$. The unemployment rate falls quite gradually in this phase. If the phase persisted indefinitely, the unemployment rate would eventually stabilize at a value of

$$
0.0605 /(1-0.8584-0.1217)=3.04,
$$

though it would take 30 years of expansion to get there; in the first year of the expansion, the unemployment rate would drop only 0.6 percent.

By contrast, if the economy started with $y_{t}=3.0$ and entered the mild recession phase, the unemployment rate would rise much more quickly than it fell, reaching 5.4 percent within a year (see Panel B of Figure 5). And if the economy starts with unemployment at 6 percent and enters the severe recession phase (Panel C), the rate would reach nearly 12 percent after a year.

This asymmetry in unemployment dynamics is subtle in the statistical sense that the baseline model (4) adequately captures most of the gross features of the data. But it seems extremely important from an economic perspective. For once we agree that up and down movements in the unemployment rate occur at different speeds, the notion that they may be caused by different economic forces becomes much more appealing. Finding this kind of nonlinearity using modern statistical methods could thereby be interpreted as exonerating to some degree the assumptions of early students of the business cycle. Specifically, it suggests that there is a real event associated with the label of an "economic recession," which is measurable by objective statistical methods as a change in the dynamic behavior of the unemployment rate. It further suggests that the key task for business cycle theorists should not be to look for a unification between the explanation of shortrun dynamics and long-run growth, but rather to identify the factors that can result in a temporary failure of the economy to utilize efficiently the available labor, capital, and technology. 
Figure 5

\section{Simulated Time Path for Unemployment Under Three Scenarios}

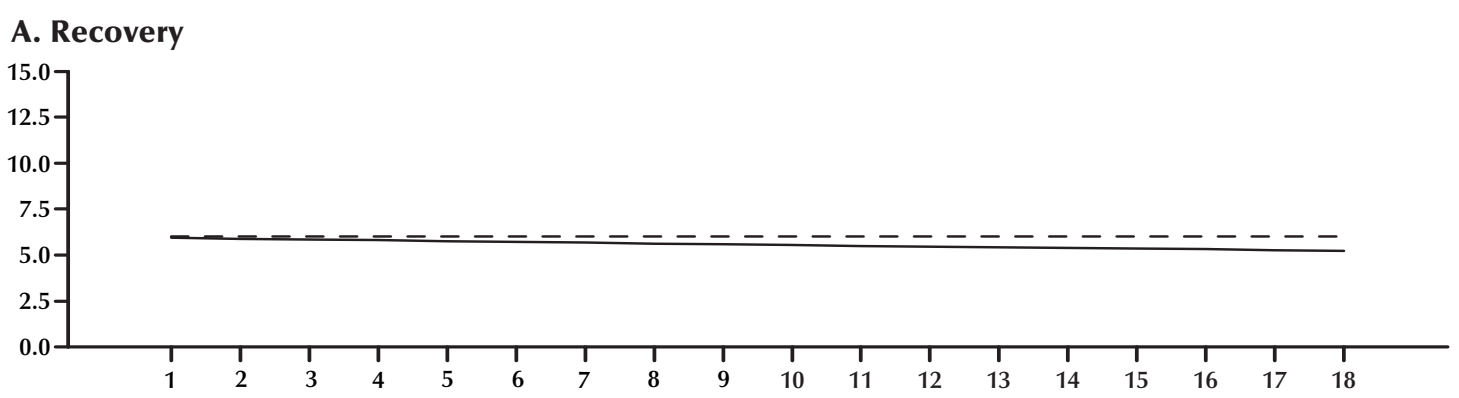

B. Mild Recession

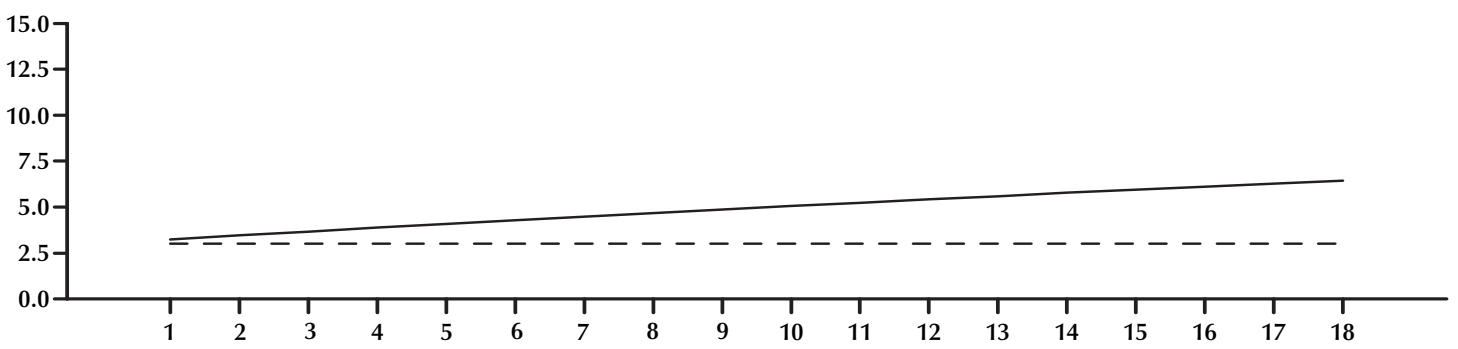

C. Severe Recession

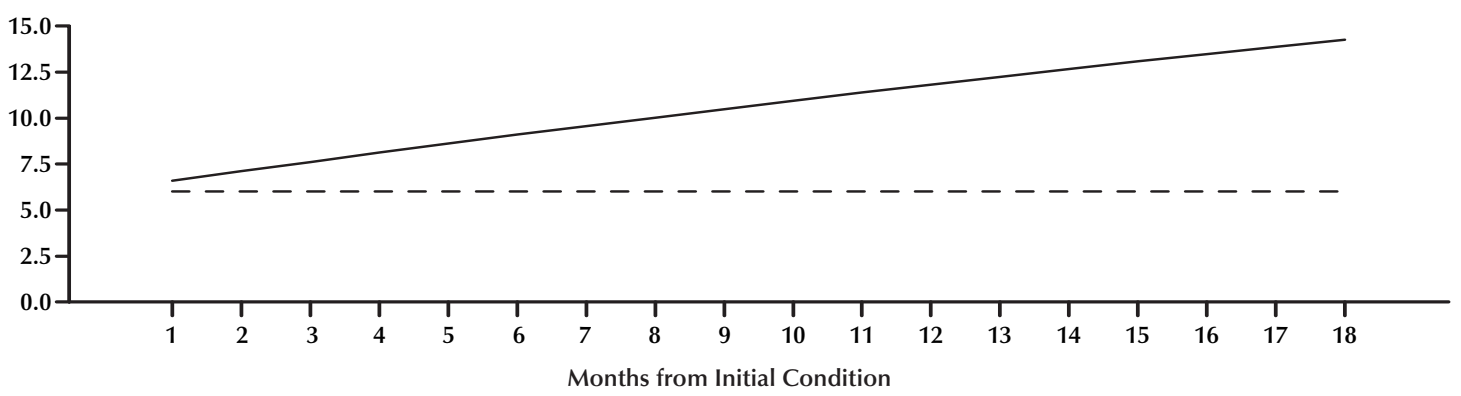

NOTE: In Panel A, unemployment is initially at 6 percent and the economy remains in regime 1 with no further shocks; in Panel B, unemployment is initially at 3 percent and the economy remains in regime 2 with no further shocks; in Panel C, unemployment is initially at 6 percent and the economy remains in regime 3 with no further shocks.

\section{THE BEHAVIOR OF INTEREST RATES}

I argued above that the business cycle is not an artificial categorization existing only in the imagination of economists but rather is an integral part of the real data-generating process. In addition to believing that such patterns exist, early students of the business cycle also differed from their modern counterparts in the degree to which financial factors were viewed as a key part of the business cycle. For example, Burton (1902) described the typical business downturn in the following terms:

The usual signal for the beginning of a crisis is a conspicuous banking or mercantile failure, or the exposure of some fraudulent enterprise which attracts wide-spread attention. Money is hoarded. Credit is refused. (Burton, 1902)

As a first look at some of the evidence that may have inspired such an opinion, consider Figure 6, 


\section{Figure 6}

\section{Monthly Short-Term Commercial Paper Rates in New York City, 1857:01-1937:01}

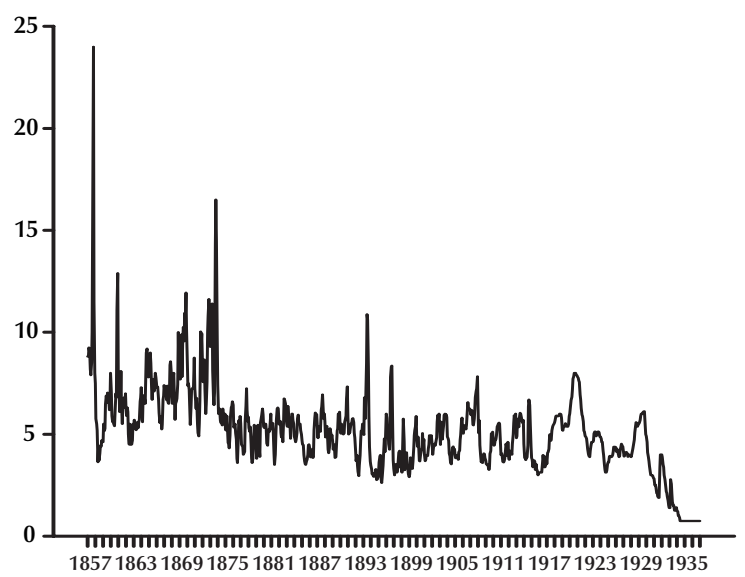

which plots the series on commercial paper rates in New York city compiled by Macaulay (1938). ${ }^{5}$ These data behave very differently before and after the founding of the U.S. Federal Reserve in 1913, a point to which we will want to return shortly. But first consider the behavior of this series prior to 1913. There is at least one asymmetry that Figure 1 and Figure 6 have in common, induced per force by the fact that neither the unemployment rate nor the nominal interest rate can ever go negative, but both can go and occasionally have gone quite far above their usual levels. Notwithstanding, interest rates do not display the same obvious pattern of ups and downs as the unemployment data in Figure 1. Indeed, apart from seasonal fluctuations stemming from the predominance of agriculture in the economy over this period, such predictable swings might be difficult to reconcile with the view that asset markets function efficiently given investors' ability to arbitrage between securities of different maturities. Nevertheless, there are a number of interest-rate spikes prior to 1913 that are quite dramatic visually and

5 Taken from Macaulay (1938, Column 3, Table 10, pp. A142-61). Macaulay describes these as "choice 60-90 day two name paper" up to 1923 and "four to six month prime double and single name paper" from 1924 on.

\section{Figure 7}

\section{Estimated Spectrum of U.S. Monthly Short- Term Commercial Paper Rates, 1857:01-1913:12}

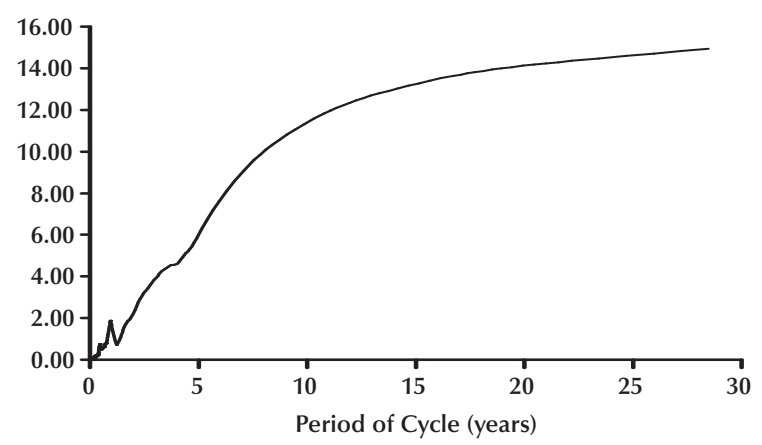

NOTE: Plotted as a function of the period of the cycle in years.

that have been delegated particular names as important points of reference for economic historians, names such as the Crisis of 1857, Crisis of 1873, or the Panic of 1893.

As in the case of postwar unemployment rates, there is no obvious periodicity to the occurrence of these interest rate spikes. Figure 7 plots the spectrum of interest rates over the 1857:01 to 1913:12 period, which again is dominated by the lowest frequencies. There is a noticeable local peak associated with cycles of a 12-month period, reflecting the tendency of interest rates to be highest in the winter months when agricultural borrowing needs were greatest. But again there is no mass noticeable for what are often described as "business cycle frequencies," namely, cycles with periods of 3 to 5 years.

For a baseline model, we estimated a slight generalization of the model in equations (1) through (3) to allow for a possible seasonal pattern in interest rates, replacing equation (2) with

$$
\begin{aligned}
& u_{t}=z_{t}-\phi_{1} z_{t-1}-\phi_{2} z_{t-2} \\
& z_{t}=y_{t}-c-\gamma \cos (\pi t / 6)
\end{aligned}
$$

for $y_{t}$ now the interest rate and $t=1$ corresponding to the January 1857 observation. A positive value of $\gamma$ would reflect the tendency for interest rates to peak around December. The likelihood was then 
Table 3

Maximum Likelihood Estimates of the Baseline Model for Nineteenth-Century Interest Rates

\begin{tabular}{lccc} 
Symbol & Explanation & MLE & Standard error \\
\hline$c$ & Typical interest rate & 5.11 & 0.18 \\
$\phi_{1}$ & First AR coefficient & 1.104 & 0.031 \\
$\phi_{2}$ & Second AR coefficient & -0.212 & 0.026 \\
$\gamma$ & Effect of seasonal & 0.444 & 0.070 \\
$\sigma$ & Scale factor & 0.407 & 0.021 \\
$v$ & Degrees of freedom & 2.28 & 0.24 \\
\hline
\end{tabular}

\section{Table 4}

\section{Comparison of Selected Models of Nineteenth-Century Interest Rates}

\begin{tabular}{lccc} 
Model & No. of parameters & Log likelihood & Schwarz criterion \\
\hline Gaussian AR(2) & 5 & -932.67 & -948.99 \\
Student $t$ AR(2) & 6 & -677.05 & -696.63 \\
Student $t$ AR $(2)$ with MS variance & 9 & -633.58 & -662.95
\end{tabular}

NOTE: All models also include cosine seasonal. Schwarz criterion calculated as $\mathfrak{L}-(k / 2) \log (T)$ for $\mathfrak{L}$ the $\log$ likelihood, $k$ the number of parameters, and $T=682$ the sample size.

maximized numerically over 1857:03 to 1913:12, resulting in the estimates reported in Table 3. Once again, allowing Student $t$ innovations implies a huge improvement in the log likelihood over a Gaussian specification (see Table 4).

Apart from the seasonal cycle in agriculture, economic theory would lead us to expect that changes in interest rates are much harder to forecast than the unemployment rate. A Markovswitching specification related to that in (5) is to allow the variance rather than the intercept to change with the regime, so that the conditional log density of the th observation is

$$
\begin{aligned}
& \log f\left(y_{t} \mid s_{t}=j, y_{t-1}, y_{t-2}, \ldots, y_{1}\right) \\
& =k_{j}-[(v+1) / 2] \log \left[1+\frac{u_{t}^{2}}{v \sigma_{j}^{2}}\right] \\
& k_{j}=\log \{\Gamma[(v+1) / 2]\}-\log \{\Gamma[v / 2]\} \\
& \quad-(1 / 2) \log \left(\sigma_{j}^{2} v \pi\right),
\end{aligned}
$$

where $u_{t}$ is again given by (7). Here we allow only two regimes, with the scale parameter taking the value $\sigma_{1}$ in the low-variance regime and $\sigma_{2}$ in the high-variance regime.

As seen in Table 4, allowing the possibility of changes in the variance parameter over time again leads to a very large improvement in the fit to the data. We can also again use the Carasco, $\mathrm{Hu}$, and Ploberger test, this time constructed for the alternative of a Markov-switching variance, as described in the appendix. The test statistic is 63.34, which vastly exceeds the 5 percent critical value of 3.68, and indeed exceeds the largest value (19.28) among any of our 1,000 Monte Carlo simulations.

The MLEs are reported in Table 5. Regime 2 is characterized by a variance of interest rate innovations that is thrice that for regime 1 , with the ergodic probabilities implying that the economy would spend about 80 percent of the time in the low-variance regime. Smoothed probabilistic inferences about when U.S. interest rates were 


\section{Table 5}

\section{Maximum Likelihood Estimates of Markov-Switching Model for Nineteenth-Century Interest Rates}

\begin{tabular}{lccc} 
Symbol & Explanation & MLE & Standard error \\
\hline$c$ & Typical interest rate & 5.11 & 0.19 \\
$\phi_{1}$ & First AR coefficient & 1.079 & 0.040 \\
$\phi_{2}$ & Second AR coefficient & -0.178 & 0.039 \\
$\gamma$ & Effect of seasonal & 0.441 & 0.064 \\
$\sigma_{1}$ & Scale factor in regime 1 & 0.612 & 0.019 \\
$\sigma_{2}$ & Scale factor in regime 2 & 1.093 & 0.092 \\
$p_{11}$ & Probability regime 1 follows itself & 0.9867 & 0.0068 \\
$p_{22}$ & Probability regime 2 follows itself & 0.941 & 0.033 \\
$v$ & Degrees of freedom & 4.40 & 0.90
\end{tabular}

unusually volatile are graphed in the middle panel of Figure 8 and repeated in the bottom graph for comparison with NBER-dated recessions (shown as shaded regions) over this period. Those dates for which the smoothed probability of being in the high-variance regime, $\operatorname{Pr}\left(s_{t}=2 \mid y_{1}, y_{2}, \ldots, y_{T} ; \hat{\theta}\right)$, exceeds one-half are categorized in Table 6 as episodes of unusually volatile interest rates for further comparison with the dates NBER has ascribed to economic recessions. ${ }^{6}$ The correspondence between these two sets of dates is strong, but not perfect. There are a half-dozen recessions in the 1880s and early 1900s, when nothing much was happening to interest rates, and one interest rate spike (in 1898) that comes in the middle of an economic expansion. A long episode of interest rate volatility in the late 1860 s and early 1870 s also correlates rather weakly with the recessions at those times. On the other hand, there are a number of other recessions, notably those of 1857-58, 1860-61, 1893, and 1896, that match up perfectly with very dramatic shifts in the interest rate regime. The suggestion thus seems strong that an important shift in the interest rate process is indeed related to some but by no means all of the nineteenth-century economic downturns.

The asymmetry found in unemployment dynamics-that unemployment rises above its average rate more quickly than it falls below its

${ }^{6}$ These can be found at www.nber.org/cycles/cyclesmain.html.

\section{Table 6}

Dates of Volatile Interest Rates and U.S. Recessions, 1857-1913

\begin{tabular}{cc} 
Volatile interest rates & Economic recessions \\
\hline 1857:03-1858:06 & $1857: 06-1858: 12$ \\
1860:09-1861:11 & $1860: 10-1861: 06$ \\
- & $1865: 04-1867: 12$ \\
1868:03-1874:02 & $1869: 06-1870: 02$ \\
- & $1873: 10-1879: 03$ \\
- & $1882: 03-1885: 05$ \\
- & $1887: 03-1888: 04$ \\
1893:03-1893:12 & $1890: 07-1891: 05$ \\
1896:07-1896:12 & $1893: 01-1894: 06$ \\
1898:03-1898:06 & $1895: 12-1897: 06$ \\
- & $1899: 06-1900: 12$ \\
- & $1902: 09-1904: 08$ \\
- & $1907: 05-1908: 06$ \\
- & $1910: 01-1912: 01$ \\
- & $1913: 01-1914: 12$
\end{tabular}

average rate-seemed to suggest rather directly that macroeconomic theorists should be looking for different explanations as to why employment rises and falls. By contrast, the deficiency of a homoskedastic linear model as a description of nineteenth-century interest rate dynamics - that interest rates are much more volatile at some times 
Figure 8

\section{Smoothed Probabilities, Commerical Paper Rates}

\section{A. Commercial Paper Rates}

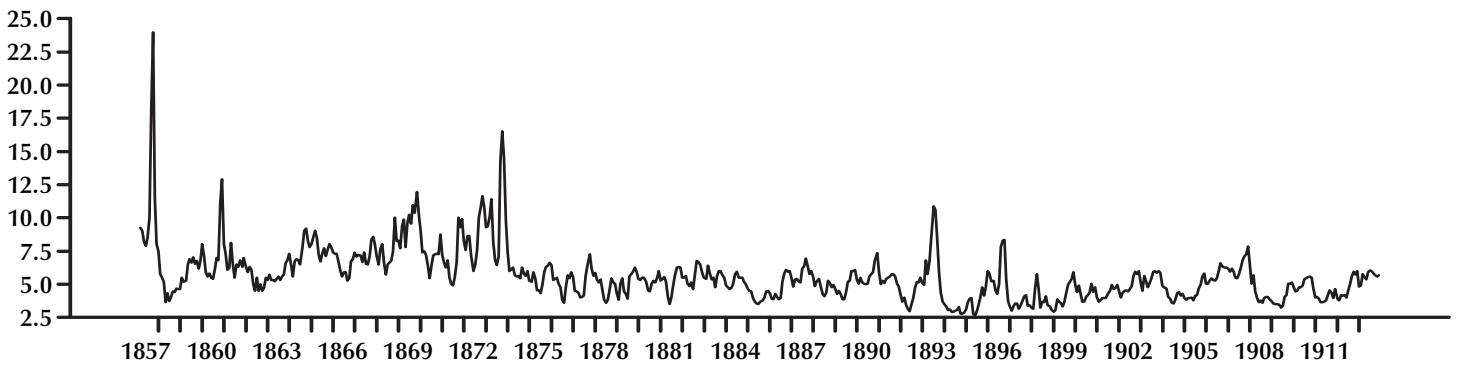

\section{B. Probability of High-Volatility State}

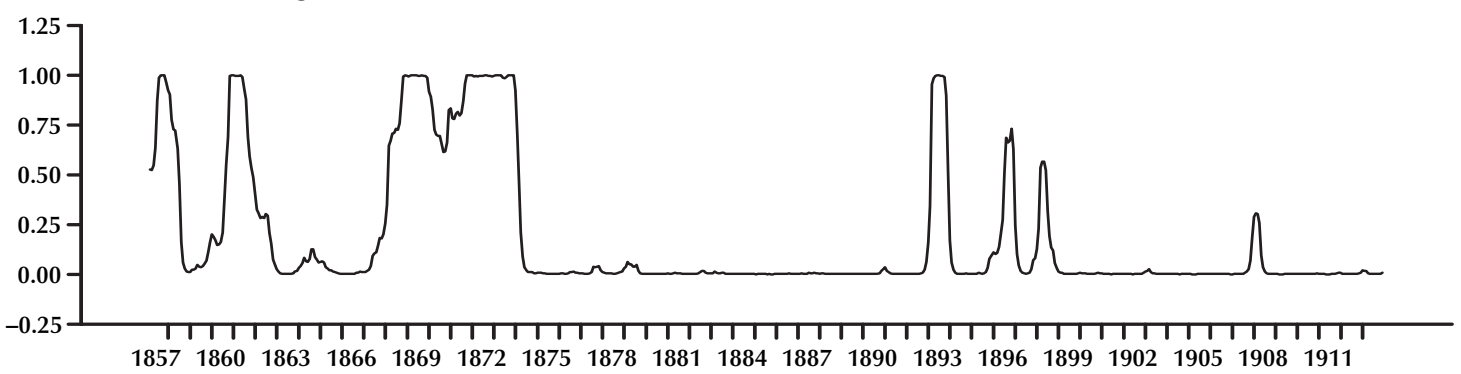

\section{NBER Recessions}

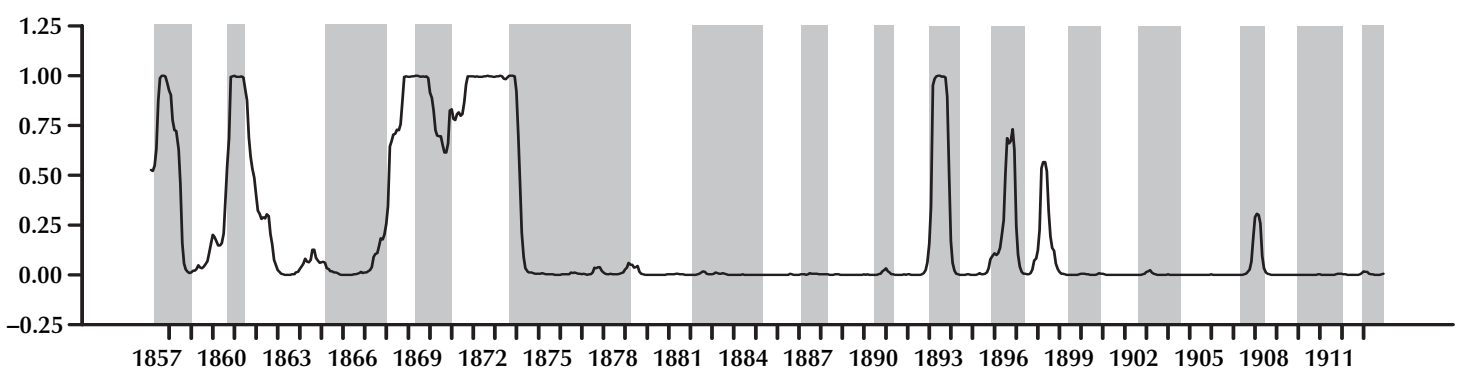

NOTE: Panel A shows interest rate data from Figure 6 for 1857:01-1913:12. Panel B shows the smoothed probability for the high-volatility interest rate regime $\left(\operatorname{Pr}\left(s_{t}=2 \mid y_{1}, y_{2}, \ldots, y_{T}, \hat{\theta}\right)\right)$ for $\hat{\theta}$ the maximum likelihood estimates reported in Table 5. Panel C shows the same series as Panel B, with NBER-dated recessions indicated as shaded areas.

than others-would be consistent with any model that implies GARCH effects on interest rates. ${ }^{7}$ However, it does seem fair to describe this finding as implying that, at least during some of the nineteenth-century recessions, interest rates were being influenced by some forces that do not oper-

7 See, for example, Granger and Machina (2004).

8 See Miron's (1986) interesting discussion of the possible relation between these two facts. ate in usual times, or, perhaps more strongly, that the financial crises emphasized by early students of the business cycle are in some important respects qualitatively different from the factors governing normal interest rate fluctuations.

It is quite apparent from Figure 6 that the behavior of short-term interest rates changed dramatically after the Federal Reserve Act in 1913, as both the seasonality and the sharp spikes in interest rates were successfully eliminated. ${ }^{8}$ However, a few broad surges in interest rates after the 


\section{Figure 9}

\section{Smoothed Probabilities, Treasury Rates}

A. 6-Month U.S. Treasury Bill Rates and Recessions, 1958:12-2004:04

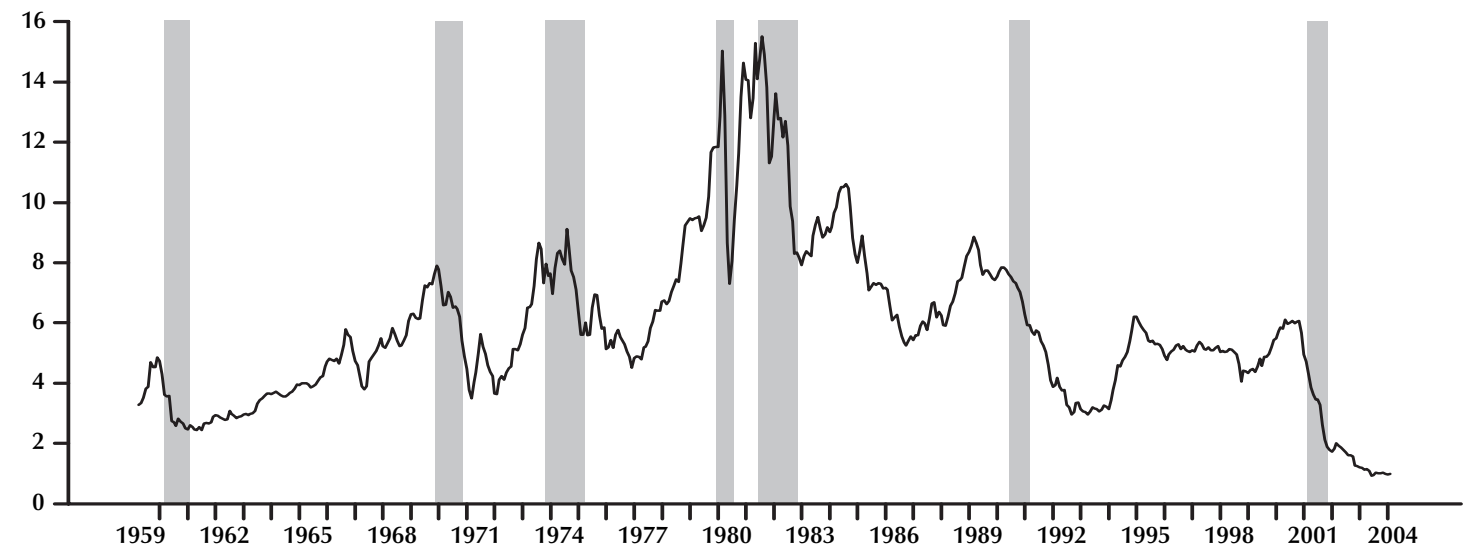

\section{B. Probability of High-Volatility State and Recessions}

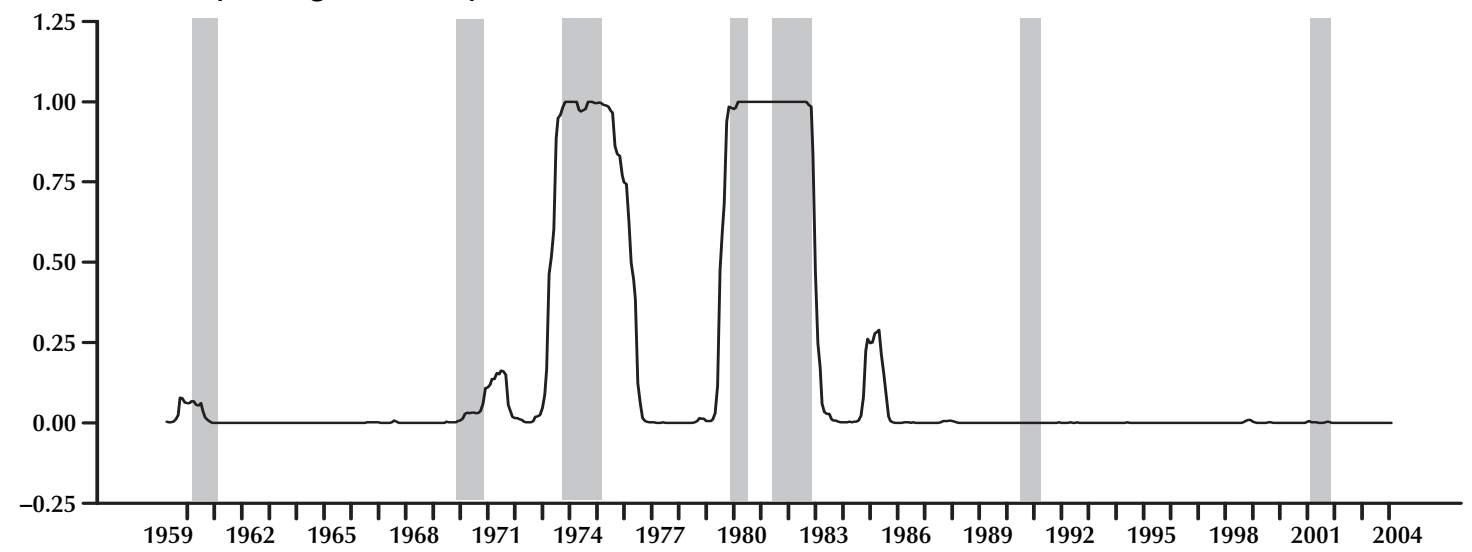

NOTE: Panel B shows the smoothed probability for the high-volatility interest rate regime $\left(\operatorname{Pr}\left(s_{t}=2 \mid y_{1}, y_{2}, \ldots, y_{T} ; \hat{\theta}\right)\right)$ for $\hat{\theta}$ the maximum likelihood estimates reported in Table 8. NBER-dated recessions are indicated as shaded areas.

founding of the Fed are certainly identifiable in the post-Fed data. These precede the economic downturn of 1920-21 and the Great Depression beginning in 1929, in addition to a minor spike coinciding with the worsening economic situation in $1931 .{ }^{9}$ This post-Fed correlation led many economists to conclude that the contribution of liquidity crunches to economic downturns did not end with the founding of the Federal Reserve.

9 Among the many who discuss these events are Friedman and Schwartz (1963) and Hamilton $(1987,1988)$.
Indeed, there is some indication that this pattern is a characteristic of postwar business cycles as well. The top panel of Figure 9 displays U.S. 6-month Treasury bill rates ${ }^{10}$ from 1958:12 to 2004:04 along with U.S. recessions as shaded areas. Again one's eye is tempted to see a recurrent tendency for the interest rate to surge upward prior to every postwar recession, though the pat-

${ }^{10}$ These are averages over business days during the month from the secondary market. Data are from the Federal Reserve Economic Database (FRED ${ }^{\circledR}$ II) of the Federal Reserve Bank of St. Louis: http://research.stlouisfed.org/fred2/. 
Table 7

Comparison of Selected Models of Changes in Postwar Interest Rates

\begin{tabular}{lccc} 
Model & No. of parameters & Log likelihood & Schwarz criterion \\
\hline Gaussian AR(2) & 4 & -292.30 & -304.88 \\
Student $t$ AR(2) & 5 & -150.66 & -166.38 \\
Student $t$ AR(2) with MS variance & 8 & -87.96 & -113.13
\end{tabular}

NOTE: Schwarz criterion calculated as $\mathfrak{I}-(k / 2) \log (T)$ for $\mathfrak{Z}$ the $\log$ likelihood, $k$ the number of parameters, and $T=540$ the sample size.

Table 8

\section{Maximum Likelihood Estimates of the Markov-Switching Model for Changes in Postwar Interest Rates}

\begin{tabular}{lccc} 
Symbol & Explanation & MLE & Standard error \\
\hline $\mathrm{c}$ & Intercept & 0.0016 & 0.0096 \\
$\phi_{1}$ & First AR coefficient & 0.409 & 0.049 \\
$\phi_{2}$ & Second AR coefficient & -0.046 & 0.042 \\
$\sigma_{1}$ & Scale factor in regime 1 & 0.174 & 0.013 \\
$\sigma_{2}$ & Scale factor in regime 2 & 0.740 & 0.107 \\
$p_{11}$ & Probability regime 1 follows itself & 0.9941 & 0.0049 \\
$p_{22}$ & Probability regime 2 follows itself & 0.9635 & 0.0247 \\
$v$ & Degrees of freedom & 4.27 & 0.94 \\
\hline
\end{tabular}

tern is more convincing for some recessions than for others.

Bansal and Zhou (2002), Ang and Bekaert (2002), and Dai, Singleton, and Yang (2003) have used a Markov-switching framework to suggest that a connection between interest rate volatility and economic recessions also characterizes postwar data. We applied the method used to analyze nineteenth-century interest rates to postwar data, with two changes. First, the term representing the agricultural seasonal was dropped. Second, we estimated the model in differences rather than levels. The reason is that levels estimation results in one root that is virtually unity, which rarely introduces numerical problems when maximizing the log likelihood for simulated samples in the Monte Carlo calculation of the Carasco, $\mathrm{Hu}$, and Ploberger statistic (though results to be reported here are otherwise identical for estimation in either levels or differences).
Table 7 replicates the findings of our other two data sets: The data are far better described with Student $t$ as opposed to Normal innovations, and further allowing for Markov-switching in the variance yields a further huge improvement in fit. Again the Carrasco, $\mathrm{Hu}$, and Ploberger statistic of 137.38 far exceeds the 95 percent critical value of 4.03 and indeed any value in our 1,000 Monte Carlo simulated samples.

MLEs are reported in Table 8. The standard deviation of the innovation is four times as large in regime 2 compared with regime 1 . The bottom panel of Figure 9 plots the smoothed probability that the economy was in the high-volatility regime for each month. As in the nineteenth-century data, there appears to be a clear connection between interest rate volatility and economic recessions, at least for the recessions of 1973-75, 1980, and 1981-82, confirming Bansal and Zhou's (2002), Ang and Bekaert's (2002), and Dai, Singleton, and 
Yang's (2003) conclusions from the volatility of the term structure.

Nor is this pattern unique to the United States. For example, Neumeyer and Perri (2004) noted that domestic interest rate spikes preceded the strong economic downturns in Mexico in 1994, Brazil and Argentina in 1995, and Korea and the Philippines in 1997, each of which had important similarities with the financial crises seen repeatedly in the United States in the nineteenth century.

\section{CONCLUSION}

We now return to the question posed in the title of this paper, "What's real about the business cycle?" If an accurate statistical description of the dynamic behavior of key economic magnitudes is a time-invariant linear model such as equation (4), then the correct answer is, there is no such thing as a business cycle. In this case, we might as well stop using the phrase "the business cycle," inherited from a less-informed century, and continue with our efforts at trying to describe shortrun economic fluctuations as being governed by the same factors that determine long-run economic growth.

However, we've encountered substantial statistical evidence that there are some features of both unemployment and interest rate dynamics that are inconsistent with a time-invariant linear specification. Each of these series seems to exhibit different dynamic behavior in recessions and expansions. The unemployment rate rises more quickly than it falls, and this often occurs at the same time as rapid spikes up and then back down in short-term interest rates. If moving between such episodes is indeed what we mean by "the business cycle," then the correct answer to our question is, the business cycle is very much a real, objectively measurable phenomenon, in which case keeping both the phrase as well as the research program that the expression invites seems well worthwhile.

The paper's title is of course also a play on words, insofar as "real business cycle theory" is derived from a class of models in which short-run economic fluctuations are driven by the same real (i.e., nonmonetary) factors that are responsible for long-run growth. Our findings cast some doubt on the claim that the business cycle is "real" in this sense. The observation that the dynamics change over the course of the business cycle suggests instead that the forces that cause employment to rise may be quite different from those that cause it to fall. Furthermore, the coincidence of this phenomena with large rapid moves in interest rates suggests that something is disrupting the normal functioning of both labor and financial markets. It is difficult to reconcile these facts with a world view in which financial markets play no role in economic fluctuations.

\section{REFERENCES}

Ang, Andrew and Bekaert, Geert. "Regime Switches in Interest Rates." Journal of Business and Economic Statistics, 2002, 20(2), pp. 163-82.

Bansal, Ravi and Zhou, Hao. "Term Structure of Interest Rates with Regime Shifts.” Journal of Finance, 2002, 57, pp. 1997-2043.

Brock, William A. and Mirman, Leonard J. "Optimal Economic Growth and Uncertainty: The Discounted Case." Journal of Economic Theory, 1972, 4, pp. 479-513.

Burns, Arthur F. and Mitchell, Wesley C. Measuring Business Cycles. New York: National Bureau of Economic Research, 1946.

Burton, Theodore E. Financial Crises and Periods of Industrial and Commercial Depression. New York: D. Appleton \& Co., 1902.

Carrasco, Marine; Liang, $\mathrm{Hu}$ and Werner, Ploberger. “Optimal Test for Markov Switching.” Working paper, University of Rochester, 2004.

Dai, Qiang; Singleton, Kenneth J. and Yang, Wei. "Regime Shifts in a Dynamic Term Structure Model of U.S. Treasury Bond Yields.” Working paper, Stern School of Business, New York University, 2003.

DeLong, J. Bradford and Summers, Lawrence. “Are 


\section{Hamilton}

Business Cycles Symmetrical?” in Robert J. Gordon, ed., The American Business Cycle. Volume 25.

Chicago: National Bureau of Economic Research and University of Chicago Press, 1986.

Fisher, Irving. Booms and Depressions: Some First Principles. New York: Adelphi, 1932.

Friedman, Milton. The Optimum Quantity of Money and Other Essays. Chicago: Aldine, 1969.

Friedman, Milton and Schwartz, Anna J. A Monetary History of the United States, 1867-1960. Princeton, NJ: Princeton University Press, 1963.

Garcia, Rene. "Asymptotic Null Distribution of the Likelihood Ratio Test in Markov Switching Models.” International Economic Review, 1998, 39, pp. 763-88.

Granger, Clive W.J. and Machina, Mark J. "Structural Attribution of Observed Volatility Clustering." Working paper, University of California, San Diego, 2004.

Hamilton, James D. "Monetary Factors in the Great Depression." Journal of Monetary Economics, 1987, 19, pp. 145-69.

Hamilton, James D. "The Role of the International Gold Standard in Propagating the Great Depression.” Contemporary Policy Issues, April 1988, 6(2), pp. 67-89.

Hamilton, James D. Time Series Analysis. Princeton, NJ: Princeton University Press. 1994.

Hamilton, James D. "Specification Testing in MarkovSwitching Time-Series Models.” Journal of Econometrics, 1996, 70, pp. 127-57.

Hansen, Bruce E. “The Likelihood Ratio Test under Non-Standard Conditions." Journal of Applied Econometrics, December 1992, 7(Supplement), pp. S61-82; "Erratum,” March/April 1996, 11(2), pp. 195-98.

Kydland, Finn E. and Prescott, Edward C. "Time to Build and Aggregate Fluctuations.” Econometrica, 1982, 50, pp. 1345-70.
Macaulay, Frederick R. The Movements of Interest Rates, Bond Yields and Stock Prices in the United States since 1856. New York: National Bureau of Economic Research, 1938.

Miron, Jeffrey A. "Financial Panics, the Seasonality of the Nominal Interest Rate, and the Founding of the Fed." American Economic Review, 1986, 76, pp. 125-40.

Mitchell, Wesley C. Business Cycles: The Problem and Its Setting. New York: National Bureau of Economic Research, 1927.

Mitchell, Wesley C. What Happens During Business Cycles. New York: National Bureau of Economic Research, 1951.

Montgomery, Alan L.; Zarnowitz, Victor; Tsay, Ruey S. and Tiao, George C. "Forecasting the U.S. Unemployment Rate." Journal of the American Statistical Association, 1998, 93, pp. 478-93.

Neumeyer, Pablo A. and Perri, Fabrizio. "Business Cycles in Emerging Economies: The Role of Interest Rates.” NBER Working Paper No. 10387, National Bureau of Economic Research, 2004.

Rothman, Philip. "Forecasting Asymmetric Unemployment Rates." Review of Economics and Statistics, 1998, 80, pp. 164-68.

Stock, James H. "Measuring Business Cycle Time." Journal of Political Economy, 1987, 95, pp. 1240-61.

Stock, James H. "Estimating Continuous Time Processes Subject to Time Deformation: An Application to Postwar U.S. GNP.” Journal of the American Statistical Association, 1988, 83, pp. 7785.

van Dijk, Dick; Franses, Philip Hans and Paap, Richard. "A Nonlinear Long Memory Model, with an Application to U.S. Unemployment." Journal of Econometrics, 2002, 110, pp. 135-65. 


\section{APPENDIX}

\section{THE CARRASCO, HU, AND PLOBERGER TEST FOR MARKOV SWITCHING}

As in equation (1), let $\ell_{t}(\theta)$ denote the conditional log likelihood of the th observation under the null hypothesis of no Markov switching, and let $\ell_{t}^{(1)}(\theta)$ and $\ell_{t}^{(2)}(\theta)$ denote its first and second derivatives with respect to the intercept $c$ :

$$
\begin{gathered}
\ell_{t}^{(1)}(\theta)=z_{t} u_{t} \\
\ell_{t}^{(2)}(\theta)=-z_{t}+\frac{2 z_{t}^{2} u_{t}^{2}}{v+1},
\end{gathered}
$$

where

$$
z_{t}=\frac{v+1}{v \sigma^{2}+u_{t}^{2}}
$$

Define

$$
\gamma_{t}(\rho ; \hat{\theta})=\ell_{t}^{(2)}(\hat{\theta})+\left[\ell_{t}^{(1)}(\hat{\theta})\right]^{2}+2 \sum_{s<t} p^{t-s} \ell_{t}^{(1)}(\hat{\theta}) \ell_{s}^{(1)}(\hat{\theta})
$$

where $\rho$ is a nuisance parameter characterizing the serial correlation of the Markov chain for $s_{t}$ under the alternative hypothesis of Markov switching. Finally, let $\mathbf{h}_{t}(\hat{\theta})$ denote the entire vector of derivatives evaluated at the MLE, of which $\ell_{t}^{(1)}(\hat{\theta})$ is the first element,

$$
\mathbf{h}_{t}(\hat{\theta})=\left.\frac{\partial \ell_{t}(\theta)}{\partial \theta}\right|_{\theta=\hat{\theta}}=\left[\begin{array}{c}
z_{t} \hat{u}_{t} \mathbf{x}_{t} \\
-\frac{1}{2 \hat{\sigma}^{2}}+\frac{z_{t} \hat{u}_{t}^{2}}{2 \hat{\sigma}^{2}}
\end{array}\right],
$$

for $\mathbf{x}_{t}=\left(1, y_{t-1}, y_{t-2}\right)^{\prime}$ and let $\hat{\varepsilon}_{t}(\rho ; \hat{\theta})$ denote the residual from an ordinary least squares regression of $(1 / 2) \gamma_{t}(\rho ; \hat{\theta})$ on $\mathbf{h}_{t}(\hat{\theta})$.Carrasco, Hu, and Ploberger proposed calculating

$$
C(\rho ; \hat{\theta})=\left[\max \left\{0, \frac{\sum_{t=1}^{T} \gamma_{t}(\rho)}{2{\sqrt{\sum_{t=1}^{T}\left[\hat{\varepsilon}_{t}(\rho ; \hat{\theta})\right]^{2}}}^{2}}\right]^{2}\right.
$$

and finding the maximum value of $C(\rho ; \hat{\theta})$ over a fixed range of alternatives, say, $\rho \in[0.2,0.8]$. In my applications this was achieved by calculating the value of

$$
v(\lambda ; \hat{\theta})=\frac{\sum_{t=1}^{T} \gamma_{t}(\rho(\lambda) ; \hat{\theta})}{2 \sqrt{\sum_{t=1}^{T}\left[\hat{\varepsilon}_{t}(\rho(\lambda)) ; \hat{\theta}\right]^{2}}}
$$

for

$$
\rho(\lambda)=0.2+0.6 \frac{|\lambda|}{\sqrt{\left(1+\lambda^{2}\right)}}
$$

and maximizing $v(\lambda ; \hat{\theta})$ numerically with respect to $\lambda$. 


\section{Hamilton}

Critical values for the test statistic $v$ were obtained by parametric bootstrap as follows. A total of $M=1,000$ samples each of size $T=673$ were generated from (4). For the $m$ th artificial sample, the MLE $\hat{\theta}^{(m)}$ was found by numerical search for that sample and then the function $v\left(\lambda ; \hat{\theta}^{(m)}\right)$ was maximized numerically with respect to $\lambda$. The $p$-value of the observed statistic for the original sample $v\left(\lambda^{*}, \hat{\theta}\right)$ was then estimated from the fraction of the $M$ samples for which $v\left(\lambda^{*(m)}, \hat{\theta}^{(m)}\right)$ exceeded $v\left(\lambda^{*}, \hat{\theta}\right)$.

To test the null of constant regimes against the alternative of Markov switching in the variance, we replace (8) and (9) with

$$
\begin{aligned}
& \ell_{t}^{(1)}(\theta)=-\frac{1}{2 \sigma^{2}}+\frac{z_{t} u_{t}^{2}}{2 \sigma^{2}} \\
& \ell_{t}^{(2)}(\theta)=\frac{1}{2 \sigma^{4}}+\frac{z_{t} u_{t}^{2}}{2 \sigma^{4}}-\frac{z_{t}^{2} u_{t}^{2} v}{2 \sigma^{2}(v+1)} .
\end{aligned}
$$

